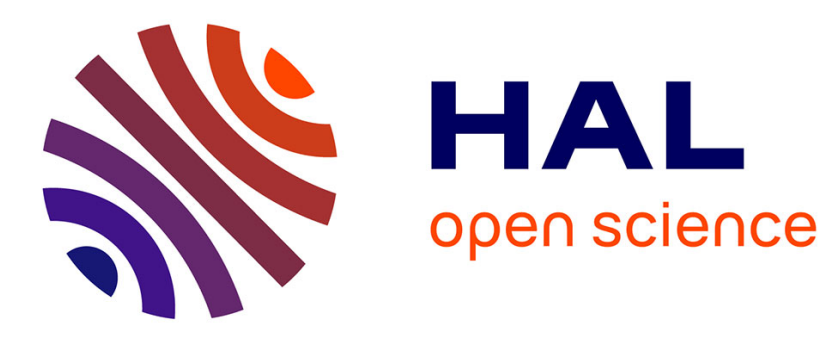

\title{
Modeling and MPPT Sensorless Control of a DFIG-Based Marine Current Turbine
}

Seifeddine Benelghali, Mohamed Benbouzid, Jean Frédéric Charpentier, Tarek Ahmed-Ali, Jean-Michel Gahery, Alexandra Denis

\section{- To cite this version:}

Seifeddine Benelghali, Mohamed Benbouzid, Jean Frédéric Charpentier, Tarek Ahmed-Ali, JeanMichel Gahery, et al.. Modeling and MPPT Sensorless Control of a DFIG-Based Marine Current Turbine. ICEM'08, Sep 2008, Vilamoura, Portugal. pp.ID 1435. hal-00531292

\section{HAL Id: hal-00531292 https://hal.science/hal-00531292}

Submitted on 2 Nov 2010

HAL is a multi-disciplinary open access archive for the deposit and dissemination of scientific research documents, whether they are published or not. The documents may come from teaching and research institutions in France or abroad, or from public or private research centers.
L'archive ouverte pluridisciplinaire HAL, est destinée au dépôt et à la diffusion de documents scientifiques de niveau recherche, publiés ou non, émanant des établissements d'enseignement et de recherche français ou étrangers, des laboratoires publics ou privés. 


\title{
Modeling and MPPT Sensorless Control of a DFIG-Based Marine Current Turbine
}

\author{
S.E. Ben Elghali ${ }^{1}$, M.E.H. Benbouzid ${ }^{1}$, J.F. Charpentier ${ }^{2}$, T. Ahmed-Ali ${ }^{1}$, J.M. Gahery ${ }^{1,2}$ and A. Denis ${ }^{1,2}$ \\ ${ }^{1}$ Laboratoire Brestois de Mécanique et des Systèmes (LBMS - EA 4325), University of Brest \\ IUT of Brest - Rue de Kergoat - CS 93837, 29238 Brest Cedex 03, France \\ E-mail: m.benbouzid@ieee.org \\ ${ }^{2}$ French Naval Academy Research Institute (IRENav - EA 3634), French Naval Academy \\ Lanveoc-Poulmic, BP 600, 29240 Brest Armées, France
}

\begin{abstract}
This paper deals with the modeling and the sensorless control of a variable speed DFIG-based marine current turbine. The proposed MPPT sensorless control strategy relies on the resource and the marine turbine models that were validated by experimental data. The sensitivity of the proposed control strategy is analyzed regarding the swell effect as it is considered as the most disturbing one for the resource model. Tidal current data from the Raz de Sein (Brittany, France) are used to run simulations of a $7.5-\mathrm{kW}$ prototype over various flow regimes. Simulation results are presented and fully analyzed.
\end{abstract}

Index Terms-Marine current turbine (MCT), Doubly-Fed Induction Generator (DFIG), modeling, sensorless control, Maximum Power Point Tracking (MPPT).

\section{NOMENCLATURE}

$\begin{array}{ll}\rho & =\text { Fluid density; } \\ A & =\text { Cross-sectional area of the marine turbine; } \\ V_{t i d e} & =\text { Fluid speed; } \\ C_{p} & =\text { Power coefficient; } \\ C & =\text { Tide coefficient; } \\ V_{s t}\left(V_{n t}\right) & =\text { Spring (neap) tide current speed; } \\ s,(r) & =\text { Stator (rotor) index (superscripts); } \\ d, q & =\text { Synchronous reference frame index; } \\ V(I) & =\text { Voltage (Current); } \\ P(Q) & =\text { Active (Reactive) power; } \\ \phi & =\text { Flux; } \\ T_{e m}\left(T_{m}\right) & =\text { Electromagnetic torque (Mechanical torque); } \\ R & =\text { Resistance } \\ L(M) & =\text { Inductance (Mutual inductance); } \\ \sigma & =\text { Total leakage coefficient, } \sigma=1-M^{2} / L_{s} L_{r} ; \\ \theta_{r} & =\text { Rotor position; } \\ \omega_{r}\left(\omega_{s}\right) & =\text { Angular speed (Synchronous speed); } \\ s l & =\text { Slip; } \\ f & =\text { Viscosity coefficient; } \\ J & =\text { Rotor Inertia; } \\ p & =\text { Pole pair number; } \\ s & =\text { Derivative operator. }\end{array}$

This work is supported by Brest Métropole Océane (BMO) and the European Social Fund (ESF). It is also supported by the GDR SEEDS CNRS $\mathrm{N}^{\circ} 2994$ under the Internal Project HYDROLE. It is done within the framework of the Marine Renewable Energy Commission of the Brittany Maritime Cluster (Pôle Mer Bretagne).

\section{INTRODUCTION}

Only a fraction of the global ocean energy resource is to be found in sites which are economically feasible to explore with available technology. However, this fraction could still make a considerable contribution to electricity supply. This is the reason why the marine renewable sector is currently the focus of much industrial and academic research around the world [1]. Sites with attractive wave climate and intense tidal currents are abundant in the vicinity of the European coastline. It has been shown that $48 \%$ of the European tidal resource is in the UK, $42 \%$ in France, and $8 \%$ in Ireland. Three examples in France are shown in Fig. 1. The Raz Blanchard situated in Cap de la Hague experiences extreme tidal currents exceeding 8 knots and leading to a large amount of kinetic energy flux.

There are basically two ways of generating electricity from marine and tidal currents: by building a tidal barrage across an estuary or a bay in high tide areas, or by extracting energy from free flowing water (tidal kinetic energy). Within the last few decades, developers have shifted towards technologies that capture tidally-driven coastal currents or tidal stream [2]. The astronomic nature of this resource makes it predictable, to within $98 \%$ accuracy for decades, and independent of prevailing weather conditions. This predictability is critical to a successful integration of renewable energy in the electrical grid [3].

In this context, it is obvious that there is a need to quantify the potential to generating electricity from these various sites [4]. This paper deals then with the modeling and the sensorless control of a variable speed DFIG-based marine current turbine. The proposed MPPT sensorless control strategy is tested using tidal current data from the Raz de Sein (Brittany, France) for a $7.5-\mathrm{kW}$ prototype over various flow regimes. It should be noted that when scanning the literature, one will find very few papers in this topic [5].

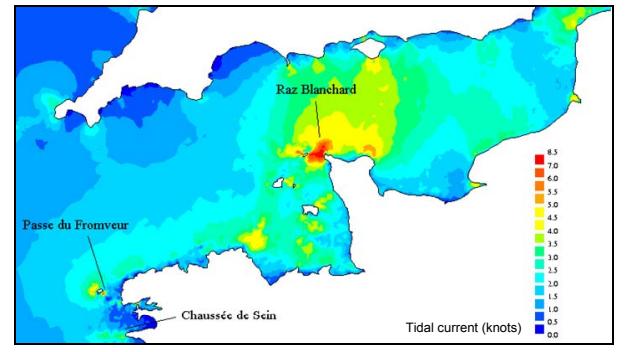

Fig. 1. Raz Blanchard, Fromveur, and Raz de Sein and sites in the French western coast. 


\section{Marine CURRENT TURBINE MODELING}

The global scheme for a grid-connected marine current turbine is given by Fig. 2 .

\section{A. The Resource Model}

1) Resource Potential. The total kinetic power in a marine current turbine has a similar dependence to that of a wind turbine and is governed by the following equation [6-7].

$P=\frac{1}{2} \rho A V_{\text {tide }}^{3}$

However, a marine energy turbine can only harness a fraction of this power due to losses and (1) is modified as follows.

$P=\frac{1}{2} \rho C_{p} A V_{\text {tide }}^{3}$

For marine turbines, $C_{p}$ is estimated to be in the range $0.35-0.5[8]$.

2) Resource Model. Tidal current data are given by the SHOM (French Navy Hydrographic and Oceanographic Service) and is available for various locations in chart form. The SHOM available charts give, for a specific site, the current velocities for spring and neap tides. These values are given at hourly intervals starting at 6 hours before high waters and ending 6 hours after. Therefore, knowing tides coefficient, it is easy to derive a simple and practical model for tidal current speeds $V_{\text {tide }}$.

$V_{\text {tide }}=V_{n t}+\frac{(C-45)\left(V_{s t}-V_{n t}\right)}{95-45}$

Where 95 and 45 are respectively the spring and neap tide medium coefficient.

This first-order model is then used to calculate the tidal velocity each hour. The implemented model will allow the user to compute tidal velocities in a predefined time range. Figure 3 shows the model output for a month (March 2007) and for a year (2007). This adopted resource model has several advantages including its modularity not to mention its simplicity. Indeed, the marine turbine site can be changed, the useful current velocity can be adapted, and the time range taken into account can also be adapted from one month to one year.

\section{B. The Turbine Rotor Model}

The harnessing of the energy in a tidal flow requires the conversion of kinetic energy in a moving fluid, in this case water, into the motion of a mechanical system, which can then drive a generator. It is not too surprising, therefore, that many developers suggest using technology that mirrors that which has been successfully utilized to harness the wind, which is also a moving fluid [2]. Moreover, much of the technology is based upon the use of horizontal axis turbines, such as that shown in Fig. 4. Therefore, much can be transferred from the modeling and operation of wind turbines [9]. There are, however, a number of fundamental differences in the design and operation of marine turbines. Particular differences entail changes in force loadings, immersion depth, different stall characteristics, and the possible occurrence of cavitation [1011 .

Turbine rotor aerodynamics refers to the interaction of the wind turbine rotor with the incoming wind. The treatment of rotor aerodynamics in all current design codes is based on Glauert well-known, and well established Blade Element Momentum (BEM) theory [12]. The BEM method has therefore been used for the marine turbine rotor modeling. Indeed, it is widely used in the industry as a computational tool to predict aerodynamic loads and power of turbine rotors. It is relatively simple and computationally fast meeting the requirements of accuracy and control loop computational speed.
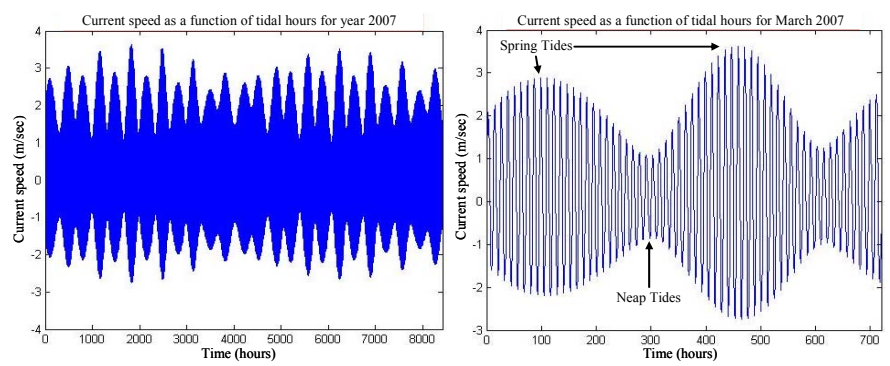

Fig. 3. Tidal velocity in the Raz de Sein for the year 2007 and March 2007.

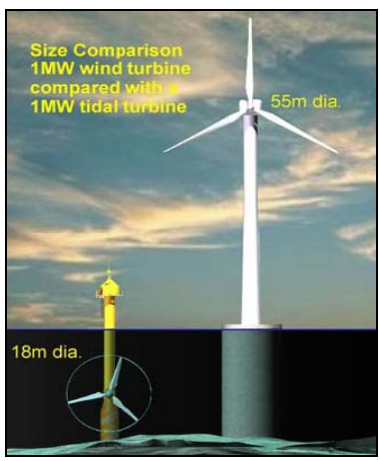

Fig. 4. Tidal turbine against an offshore wind turbine [@ MCT].

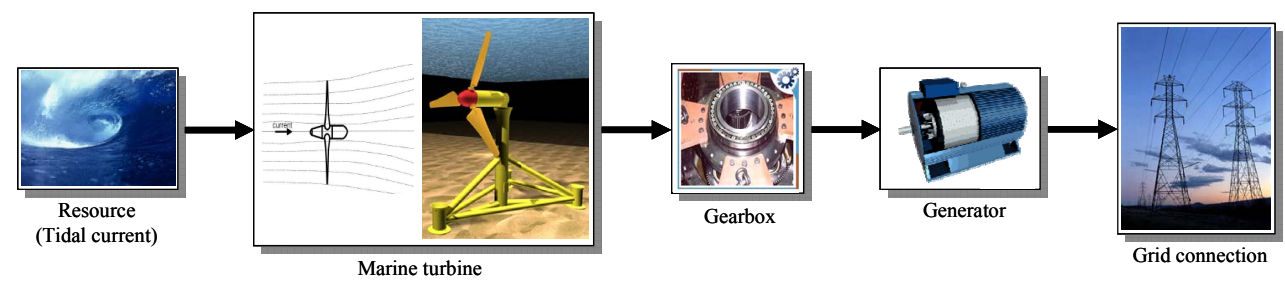

Fig. 2. Marine current turbine global scheme. 


\section{The Generator Model}

The generator chosen for the marine current system was the DFIG [13]. DFIG-based marine turbines, as for wind turbines, will offer several advantages including variable speed operation, and four-quadrant active and reactive power capabilities. Such system also results in lower converter costs and lower power losses compared to a system based on a fully fed synchronous generator with full-rated converter. Moreover, the generator is robust and requires little maintenance [5], [14]. A schematic diagram of a DFIG-based generation system is shown in Fig. 5.

The control system is usually defined in the synchronous $d$ $q$ frame fixed to either the stator voltage or the stator flux [13]. For the proposed control strategy, the generator dynamic model written in a synchronously rotating frame $d-q$ is given by the following equation.

$$
\left\{\begin{array}{l}
\frac{d \phi_{d s}}{d t}=V_{d s}+R_{s} I_{d s}+\omega_{s} \phi_{q s} \\
\frac{d \phi_{q s}}{d t}=V_{q s}+R_{s} I_{q s}-\omega_{s} \phi_{d s} \\
\frac{d \phi_{d r}}{d t}=V_{d r}+R_{r} I_{d r}+\omega_{r} \phi_{q r} \\
\frac{d \phi_{q r}}{d t}=V_{q r}+R_{r} I_{q r}-\omega_{r} \phi_{d r} \\
\phi_{d s}=-L_{s} I_{d s}-M I_{d r} \\
\phi_{q s}=-L_{s} I_{q s}-M I_{q r} \\
\phi_{d r}=-L_{r} I_{d r}-M I_{d s} \\
\phi_{q r}=-L_{r} I_{q r}-M I_{q s} \\
T_{e m}=p M\left(I_{q s} I_{d r}-I_{d s} I_{q r}\right) \\
J \frac{d \omega}{d t}=T_{e m}-T_{m}-f \omega
\end{array}\right.
$$

\section{The Variable Speed Control Strategy}

For variable speed control, torque control is needed [1517]. Therefore, using the above DFIG model, the electromagnetic torque could be expressed by

$$
T_{e m}=p \frac{M}{L_{s}} \phi_{d s} I_{q r}
$$

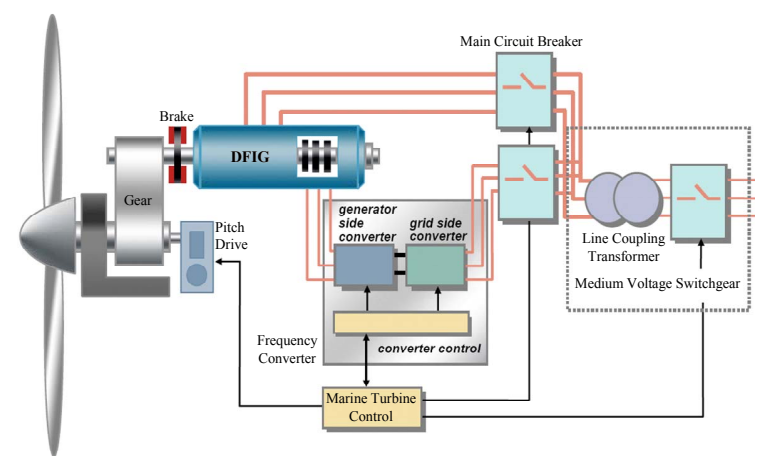

Fig. 5. Schematic diagram of a DFIG-based generation system.
Figure 6 sketches then the DFIG the overall structure which the variable control approach is based on.

As shown by (6), the DFIG control is a coupled one.

$Q_{s}=V_{q s} I_{d s}-V_{d s} I_{q s}$

For a decoupled control, a $d-q$ reference frame attached to the stator flux was used. Therefore, assuming the per phase stator resistance negligible and setting the stator flux vector aligned with the $d$-axis, the reactive power can be expressed as [13]

$Q_{s}=\frac{V_{s}}{L_{s}}\left(\phi_{s}-M I_{d r}\right)$

Since the DFIG control objective is to generate the maximum power, the speed reference is given by an MPPT strategy while setting the reactive power to zero (Fig. 7) [18].

\section{VALIDATION RESULTS}

\section{A. Validation Data and Parameters}

In this work, the Raz de Sein site was chosen above several others listed in the European Commission report EUR16683 [19] due to the presence of high speed current coupled with appropriate depths suitable for marine turbine. Moreover, the marine current speed distribution for most of the time is greater than the minimum, estimated to be $1 \mathrm{~m} / \mathrm{sec}$, required for economic deployment of marine turbine [4].

The turbine rotor model was validated through the comparison of the simulation model with experimental data from the available literature [20-21] (Fig. 8). The adopted marine current turbine is of $1.44 \mathrm{~m}$ diameter and $7.5-\mathrm{kW}$.

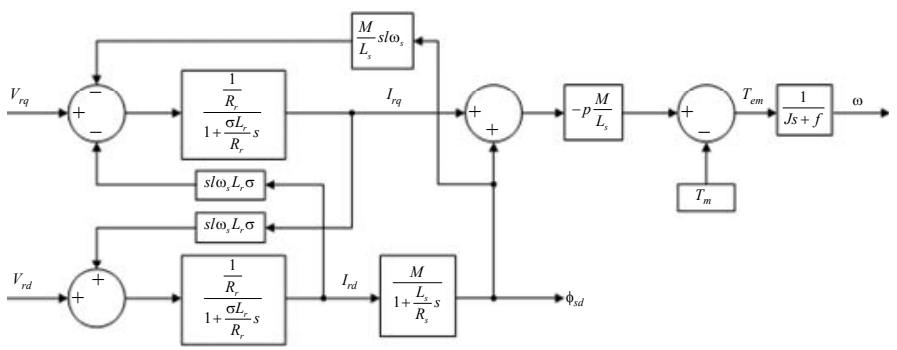

Fig. 6. Overall block scheme for DFIG variable speed control.

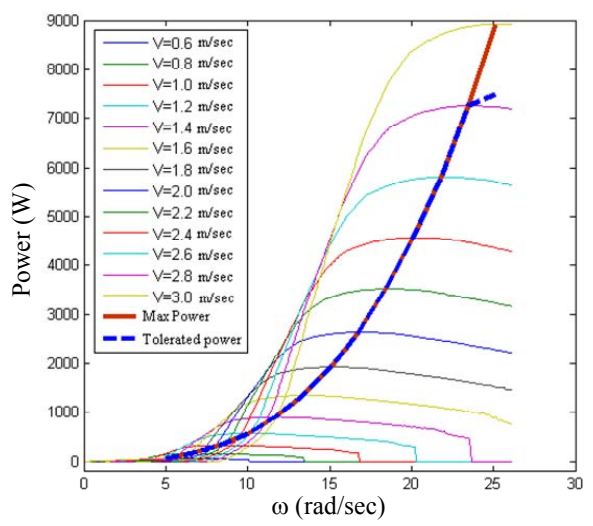

Fig. 7. Power curves for different tidal current speed. 


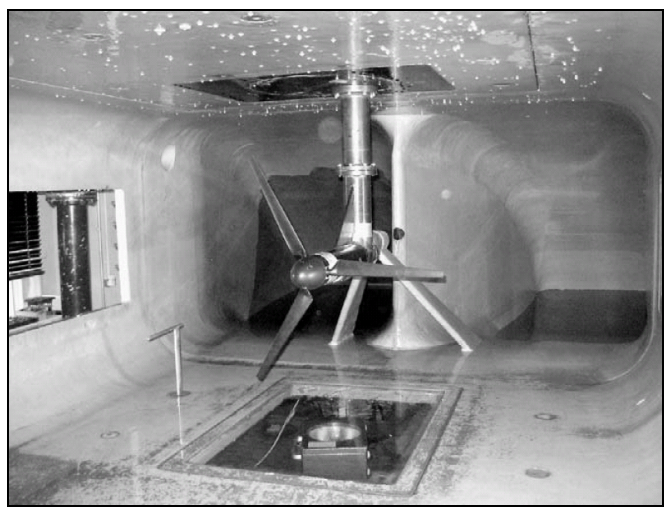

Fig. 8. The tested marine turbine [20-21].

In this context, the obtained power coefficient $C_{p}$ and the extractable power curves are shown by Fig. 9 .

The 7.5-kW DFIG parameters are given in the appendix.

\section{B. Validation Results for a Filtered Resource}

In this first case, the marine current turbine is simulated considering a resource first-order model (3). The resource is assumed to be non disturbed by sea-surface effects and by other turbulences (filtered resource).

For speed references given by Fig. 7 (MPPT) and a filtered resource, the DFIG-based MCT control performances are shown in Figs. 10 and 11 respectively illustrating the rotor speed tracking performance and the generated active power.

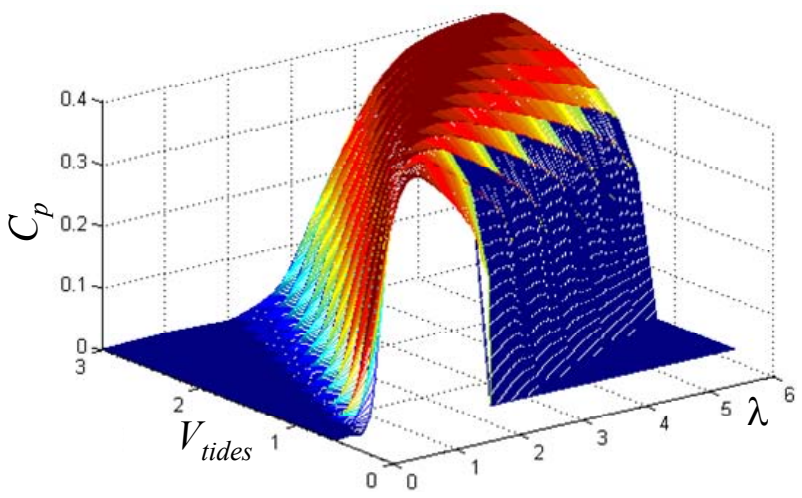

(a) $C_{p}\left(\lambda, V_{\text {tides }}\right)$ curves.

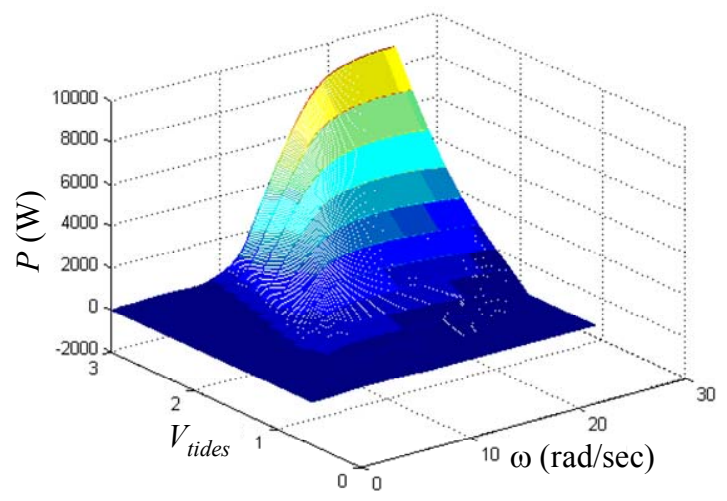

(b) The extractable power $P\left(\omega, V_{\text {tides }}\right)$.

Fig. 9.

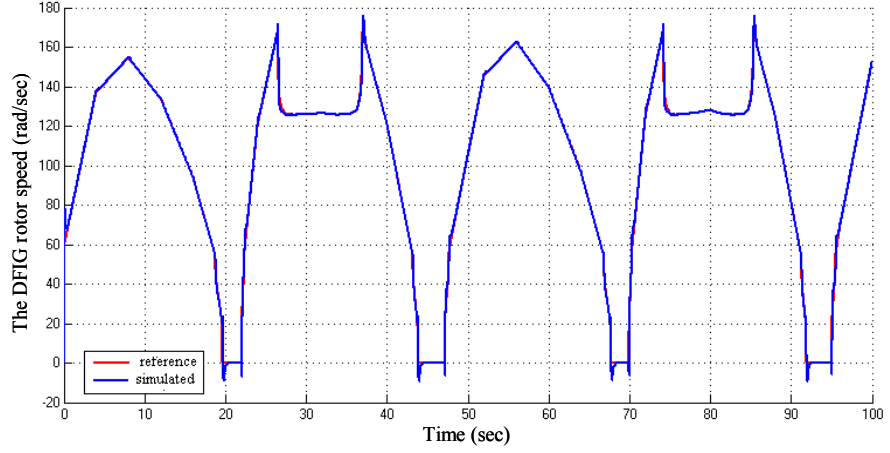

Fig. 10. The DFIG rotor speed and its reference.

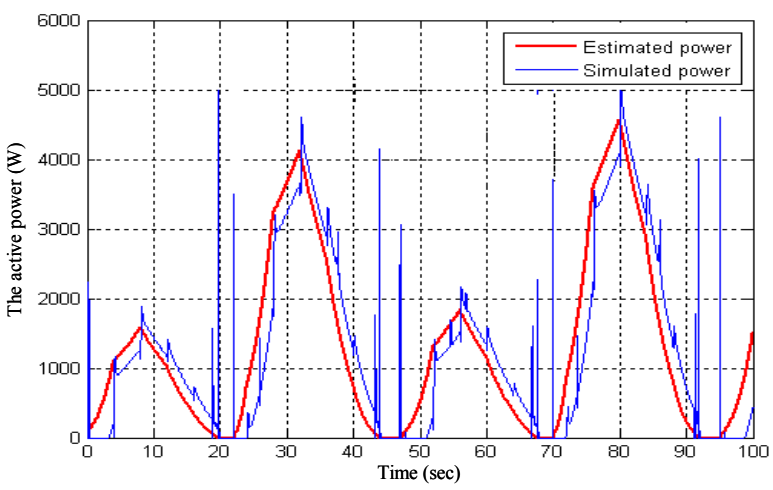

Fig. 11. The DFIG active power.

The obtained results show good tracking performances of the DFIG rotor speed. However, the active power exhibits some tracking errors of a maximum of $10 \%$. These results prove the need for direct active power control. Many works dealt with this subject and show satisfactory results [5], [13], [15], and [22]. Unfortunately, these studies did not take into account the mechanical equation. Indeed, the whole system was not simulated as it is the case for our marine current turbine.

\section{Validation Results for a Turbulent Resource}

To evaluate the resource model and its impact on the generated power, three types of resources taking into account external disturbance have been simulated in different cases summarized in Table 1. In the considered cases, simulations are carried out during $90 \mathrm{sec}$. This simulation time has been chosen to evaluate the influence of swell and sea surface effect disturbances which have time constants or periods of few seconds. In these conditions, the predicted average value of the tidal speed is assumed to be constant and equal to $2 \mathrm{~m} / \mathrm{sec}(4$ knots). It should be noted that the carried out simulations will also allow the evaluation of the predictability degree of the kinetic energy.

In the simulated cases, we consider several waveform cases for the tidal speed $\left(V_{\text {real }}\right)$ with and without disturbances. The three taken resource values are composed by the kinetic speed, the swell disturbance, and a random signal $b(t)$ that represents all the other disturbances. Several tidal speed references $\left(V_{\text {ref }}\right)$ taken as a reference for the control bloc (MPPT) are considered. 
Proceedings of the 2008 International Conference on Electrical Machines

Table 1. The simulated cases.

\begin{tabular}{|c|l|c|}
\hline Cases & \multicolumn{1}{|c|}{ Simulation Conditions / Tidal speed $(\mathrm{m} / \mathrm{sec})$} & $\begin{array}{c}\text { Power } \\
(\mathrm{kW})\end{array}$ \\
\hline 1 & $\begin{array}{l}V_{\text {real }}=2 \\
V_{\text {ref }}=2\end{array}$ & 2.535 \\
\hline 2 & $\begin{array}{l}V_{\text {real }}=2+0.3252 \cos (0.4189 t)+0.2749 \cos (0.6283 t) \\
V_{\text {ref }}=2+0.3252 \cos (0.4189 t)+0.2749 \cos (0.6283 t)\end{array}$ & 2.694 \\
\hline 3 & $\begin{array}{l}V_{\text {real }}=2+0.3252 \cos (0.4189 t)+0.2749 \cos (0.6283 t) \\
V_{\text {ref }}=2\end{array}$ & 2.612 \\
\hline 4 & $\begin{array}{l}V_{\text {real }}=2+0.3252 \cos (0.4189 t)+0.2749 \cos (0.6283 t) \\
\quad+b(t)\end{array}$ & 2.691 \\
\hline 5 & $\begin{array}{l}V_{\text {ref }}=2 \\
\text { real }\end{array}$ & \\
\hline & $V_{\text {real }}=2+b(t)$ & $2.0 .3252 \cos (0.4189 t)+0.2749 \cos (0.6283 t)$ \\
\hline
\end{tabular}

In particular, the DFIG-based MCT performances are evaluated when a perturbed resource is associated to a constant reference tidal speed (case 1,2, and 4). These cases allow the use of the tidal predicted average speed as a reference for the MPPT calculations and therefore allow a sensorless control (no needs for tidal speed sensor for the MCT).

Since the swell effect is considered as the most disturbing one for our resource model, a swell Stoke model is added. In this case, the speed potential is given by (Fig. 12)

$$
\left\{\begin{array}{l}
V_{\text {tides }}=\operatorname{grad} \phi \\
\phi=-\frac{H L}{2 T} \frac{\operatorname{ch} 2 \Pi\left(\frac{z+d}{L}\right)}{\operatorname{sh} 2 \Pi\left(\frac{d}{L}\right)} \sin 2 \Pi\left(\frac{t}{T}-\frac{x}{L}\right)
\end{array}\right.
$$

Figure 13 shows the DFIG rotor speeds and the corresponding generated active powers for some of Table 1 cases. It should be noted that Table 1 also gives the predicted active power for the different cases. The obtained results prove that the adopted first order model that predicts the resource tidal speed is quite efficient as a reference for the MPPT control block and can provide up to $95 \%$ of the extractable power even if the resource is heavily disturbed. Moreover, with the adopted resource model, the DFIG-based marine current turbine is not overloaded in comparison to a real tidal speed reference used for the MPPT control.

\section{CONCLUSIONS}

This paper dealt with the modeling and the control of a variable speed doubly-fed induction generator based marine current turbine. An MPPT-based control strategy was proposed for variable speed control. It relies on the resource and the marine turbine models that were validated by experimental data.

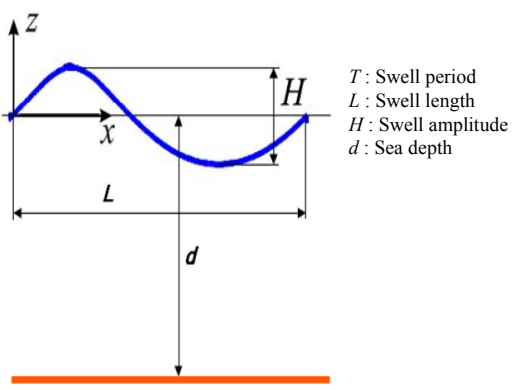

Fig. 12. Swell characteristics.
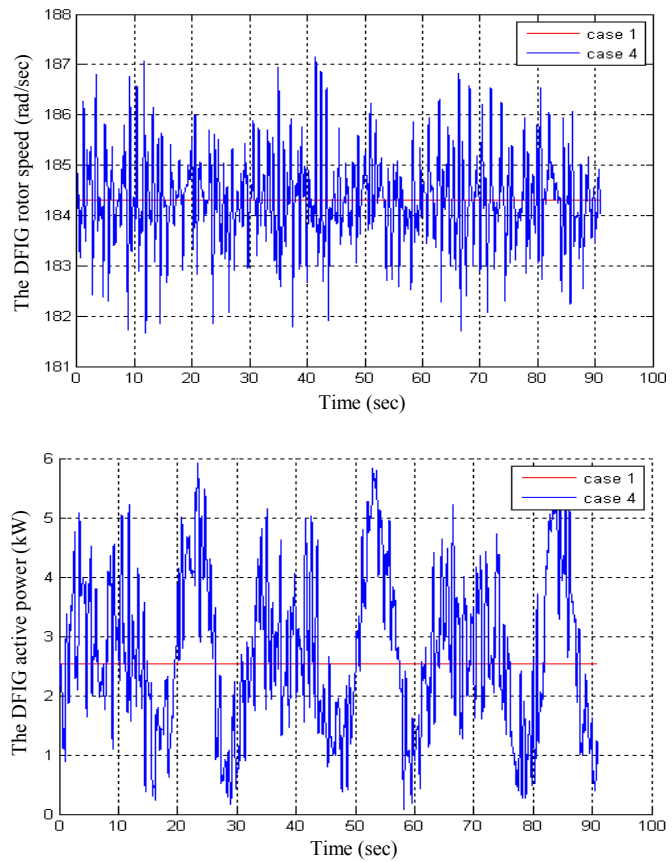

(a) Case 1 and 4 .
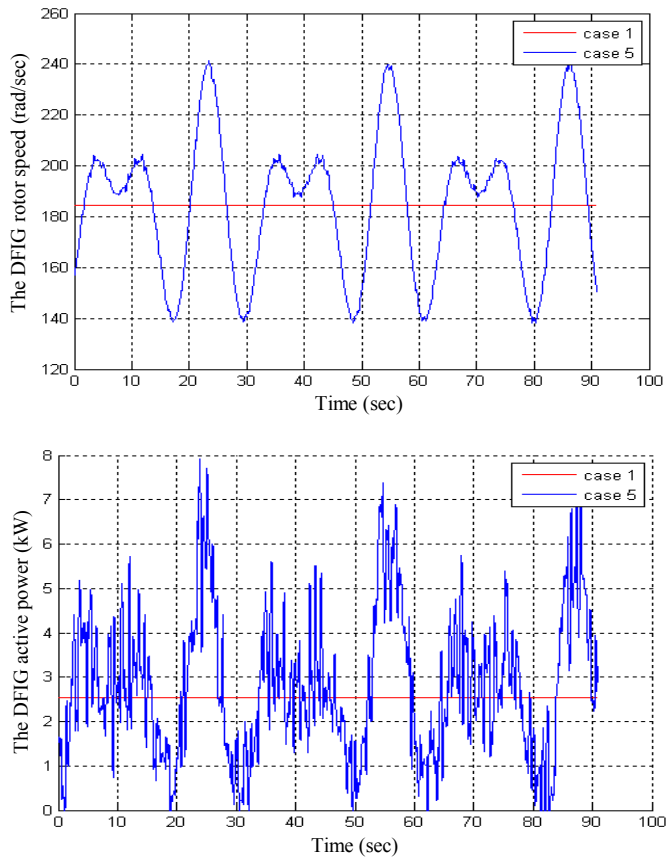

(b) Case 1 and 5 . 
Proceedings of the 2008 International Conference on Electrical Machines
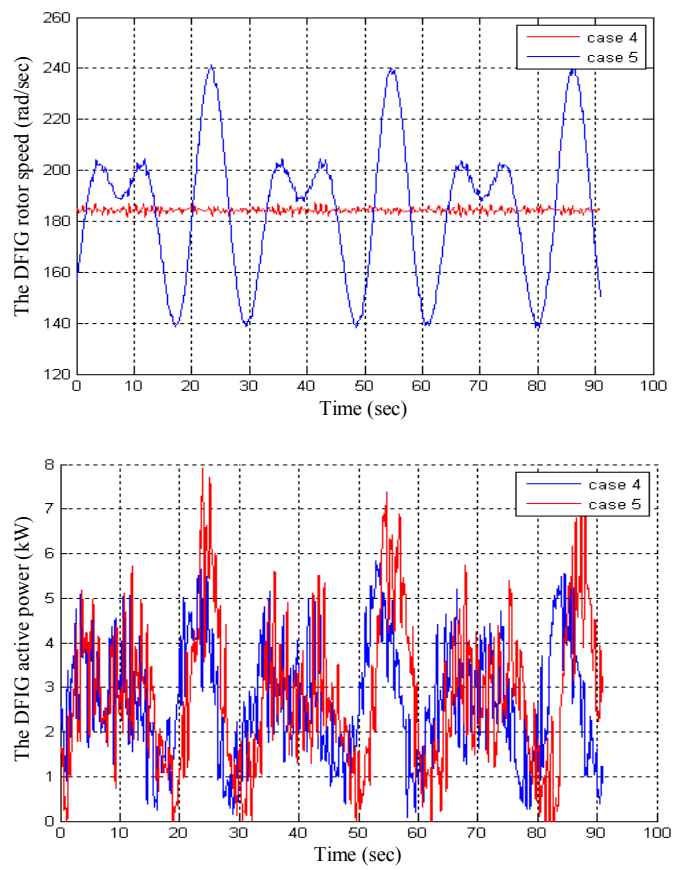

(c) Case 4 and 5 .

Fig. 13. The DFIG rotor speed and generated active power for a turbulent resource.

Tidal current data from the Raz de Sein (Brittany, France) have been used to run simulations of a $7.5-\mathrm{kW}$ prototype over various flow regimes. Simulation results show that the proposed control strategy is effective in terms of speed tracking. However, the active power exhibits some tracking errors of a maximum of $10 \%$. These results prove the need for direct active power control.

Moreover, the sensitivity of the proposed control strategy was analyzed regarding a disturbed resource including the swell effect as it is considered as the most disturbing one. The obtained results are very encouraging. Indeed, they prove that the adopted first order model that predicts the resource tidal speed is quite efficient as a reference for the MPPT control block and can provide up to $95 \%$ of the extractable power even if the resource is heavily disturbed. Furthermore, simulation results also show that a sensorless control can be applied for the marine current turbine system thanks to the predictability of the resource.

\section{APPENDIX}

PARAMETERS OF THE USED DFIG

$$
\begin{aligned}
R_{s}=0.455 \Omega, L_{s} & =0.084 \mathrm{H}, R_{r}=0.62 \Omega, L_{r}=0.081 \mathrm{H}, M=0.078 \mathrm{H} \\
J & =0.3125 \mathrm{~kg} \cdot \mathrm{m}^{2}, f=6.7310^{-3} \mathrm{Nms}^{-1}
\end{aligned}
$$

\section{REFERENCES}

[1] C.M. Johnstone et al., "EC FPVI co-ordinated action on ocean energy: A European platform ford sharing technical information and research outcomes in wave and tidal energy systems," Renewable Energy, vol. 31, pp. 191-196, 2006.

[2] M.E.H. Benbouzid et al., "Marine tidal current electric power generation technology: State of the art and current status," in Proceedings of IEEE IEMDC'07, Antalya (Turkey), vol. 2, pp. 1407-1412, May 2007.

[3] 2005 IEEE Power Engineering Society General Meeting Panel Session, "Harnessing the untapped energy potential of the oceans: Tidal, wave, currents and OTEC," San Francisco (USA), June 2005.

[4] L. Myers et al., "Simulated electrical power potential harnessed by marine current turbine arrays in the Alderney Race," Renewable Energy, vol. 30, p. 1713-1731, 2005.

[5] J.W. Park et al., "Wide speed operation of a doubly-fed induction generator for tidal current energy," in Proceedings of the IEEE IECON'2004, Busan (South Korea), vol. 2, pp. 1333-1338, 2004.

[6] J.S. Couch et al., "Tidal current energy extraction: Hydrodynamic resource characteristics," Proc. IMechE, Part M: Journal of Engineering for the Maritime, vol. 220, n4, pp. 185-194, 2006.

[7] A.S. Bahaj et al., "Fundamentals applicable to the utilisation of marine current turbines for energy production," Renewable Energy, vol. 28, pp. 2205-2211, 2003

[8] L. Myers et al., "Power output performance characteristics of a horizontal axis marine current turbine," Renewable Energy, vol. 31, pp. 197-208, 2006.

[9] E. Bossanyi, Wind Energy Handbook. New York: Wiley, 2000.

[10] W.M.J. Batten et al., "Experimentally validated numerical method for the hydrodynamic design of horizontal axis tidal turbines," Ocean Engineering, (2006), doi:10.1016/j.oceaneng.2006.04.008.

[11] W.M.J. Batten et al., "Hydrodynamics of marine current turbines," Renewable Energy, vol. 31, pp. 249-256, 2006.

[12] H. Glauert, The Elements of Airfoil and Airscrew Theory. Cambridge University Press ( $\left.2^{\text {nd }} E d.\right): 1959$.

[13] S. Müller et al., "Doubly fed induction generator systems," IEEE Industry Applications Magazine, vol. 8, n³, pp. 26-33, May-June 2002.

[14] J.M. Carrasco et al., "Power-electronic systems for the grid integration of renewable energy sources: A survey," IEEE Trans. Industrial Electronics, vol. 53, n4, pp. 1002-1016, June 2006.

[15] G. Tapia et al., "Proportional-integral regulator-based approach to wind farm reactive power management for secondary voltage control," IEEE Trans. Energy Conversion, vol. 22, n², pp. 488-498, June 2007.

[16] T.K.A. Brekken et al., "Control of a doubly fed induction wind generator under unbalanced grid voltage conditions," IEEE Trans. Energy Conversion, vol. $22, \mathrm{n}^{\circ} 1$, pp. 129-135, March 2007.

[17] A. Tapia et al., "Modeling and control of a wind turbine driven doubly fed induction generator," IEEE Trans. Energy Conversion, vol. 18, $\mathrm{n}^{\circ} 2$, pp. 194-204, June 2003.

[18] E. Koutroulis et al., "Design of a maximum power tracking system for wind-energy-conversion applications," IEEE Trans. Industrial Electronics, vol. 53, n², pp. 486-494, April 2006.

[19] EU Commission, "The exploitation of tidal marine currents," Report EUR16683EN, 1996.

[20] M.E.H. Benbouzid et al., "A simulation model for the evaluation of the electrical power potential harnessed by a marine current turbine," IEEE Journal on Oceanic Engineering, vol. 32, n 4 , pp. 786-797, October 2007.

[21] A.S. Bahaj et al., "Power and thrust measurements of marine current turbines under various hydrodynamic flow conditions in a cavitation tunnel and a towing tank," Renewable Energy, vol. 32, pp. 407-426, 2007.

[22] X. Lie et al., "Direct active and reactive power control of DFIG for wind energy generation," IEEE Trans. Energy Conversion, vol. 21, n³, pp. 750-758, September 2006. 